\title{
Sobre el origen del término bacteria: una paradoja semántica
}

\author{
Carlos Osorio
}

\section{About the origin of the term bacteria: a semantic paradox}

This review analyzes the origin of the term "bacteria", which was created by the biologist Christian G. Ehrenberg, initially to account for a single bacterial genus of the Vibrionia family and finally, to explain how this name imposed itself upon others as the formal denomination for the whole bacterial group.

Key words: Monas; vibrio; bacteria; microbiology.

Palabras clave: Monas; Vibrio; bacteria; microbiología.

Para todos los que aman

la microbiología y sus origenes

\section{Introducción}

\section{$\mathrm{L}$} os primeros microscopistas se habían dedicado a observar y describir los microorganismos que crecían en infusiones y otras variadas muestras ambientales, pero no habían establecido ninguna clasificación formal. Recordemos brevemente que el célebre holandés Antoine van Leeuwenhoek (1632-1723), con la ayuda de una simple lupa, descubrió el microcosmos de los animalículos y les denominó originalmente en holandés "kleine dierkens" (en holandés "pequeños animales" $\mathrm{y}$ en su forma latina nominativo singular animalculum o plural animalcula) ${ }^{1}$. A inicios del siglo XVIII el francés Louis Joblot, publicó su obra "Descriptions et usages de plusieurs nouveaux microscopes", en la que describió una gran variedad de microorganismos que denominó anguilas del vinagre ${ }^{2,3}$. El primer esfuerzo sistematizador lo realizó el inglés John Hill en su obra "History of Animals" de 1752, dividiendo a los animalículos en tres clases (Gimnia, Cercaria y Arthronia) y ocho géneros (siendo el más destacado Paramecia), pero su esquema fue rápidamente olvidado $^{3}$. En 1759 el microscopista alemán Martín Ledermüller (1719-1769) creó una nueva denominación para los animalículos, esto es Infusionsthierchen (cuyo significado en alemán es animalículos de infusiones), debido a que muchos de ellos crecían en infusiones de distintas sustancias como café, té y otras ${ }^{3,4}$ (Figura 1). En 1765 el anatomista alemán Heinrich August Wrisberg publicó su obra titulada "Observationum de animalculis infusoriis satura" (Variedad de observaciones sobre animales infusorios), la que legitimó ampliamente el uso del término infusorio e introdujo esta temática específica en el mundo ilustrado ${ }^{3,5}$. En 1767 el famoso taxónomo sueco Carolus Linnaeus (1707-1778), en la tardía 12ª edición de su inmortal obra "Systema naturae per regna tria naturae" (Sistema de la naturaleza en tres reinos naturales), intentó por primera vez incorporar a estos animalículos o infusorios dentro de las categorías biológicas establecidas, dentro de un único grupo o género denominado Chaos infusorium, como parte del orden Zoophyta, dentro de la clase Vermes (término latino para gusanos), y ésta a su vez dentro del reino Animalia ${ }^{6,7}$. Posteriormente, dada la dificultad evidente que creaba este nuevo grupo de seres vivos para la sistemática, Linnaeus concibió para estos extraños seres un tercer reino viviente que los incluyese sólo a ellos y que denominó reino Chaoticum ${ }^{8,9}$.

\section{Otto Friedrich Mülller}

El gran microscopista danés Otto Federico Müller (1730-1784) fue el primero en clasificar exitosamente los microorganismos denominados infusorios o animalículos (Figura 2). En 1773 fue publicada su obra titulada "Vermium terrestrium et fluviatilium" (Sobre gusanos terrestres y fluviales $)^{10}$. En ella se describió por primera vez un microorganismo infusorio que fue denominado Monas, derivado de la palabra griega monaV (unidad), $\mathrm{y}$ que ocuparía una posición prominente en el campo de la bacteriología (también esta palabra tiene un significado en el campo de la filosofía). Aún hoy, el conocido género bacteriano Pseudomonas nos recuerda a este tan ilustre predecesor. Además, en dicha obra Müller introdujo para otro grupo de infusorios el término Vibrio, derivado del verbo latino vibro, seguramente por el ágil movimiento de estos infusorios observado bajo el microscopio. Considerando los esfuerzos iniciales de Hill y Linnaeus, se puede considerar que Müller fue el primer investigador que logró

\author{
Facultad de Medicina, \\ Universidad de Chile. \\ Programa de Microbiología y \\ Micología, Instituto de Ciencias \\ Biomédicas (ICBM). \\ Recibido: 16 de marzo de 2017 \\ Correspondencia a: \\ Carlos Osorio A. \\ gonosorio@med.uchile.cl
}


Figura 1. Animales infusorios. Ledermüller MF. Mikroskopische Gemüths- und Augen-Ergötzung. 1760. Universitätsbibliothek Heidelberg.
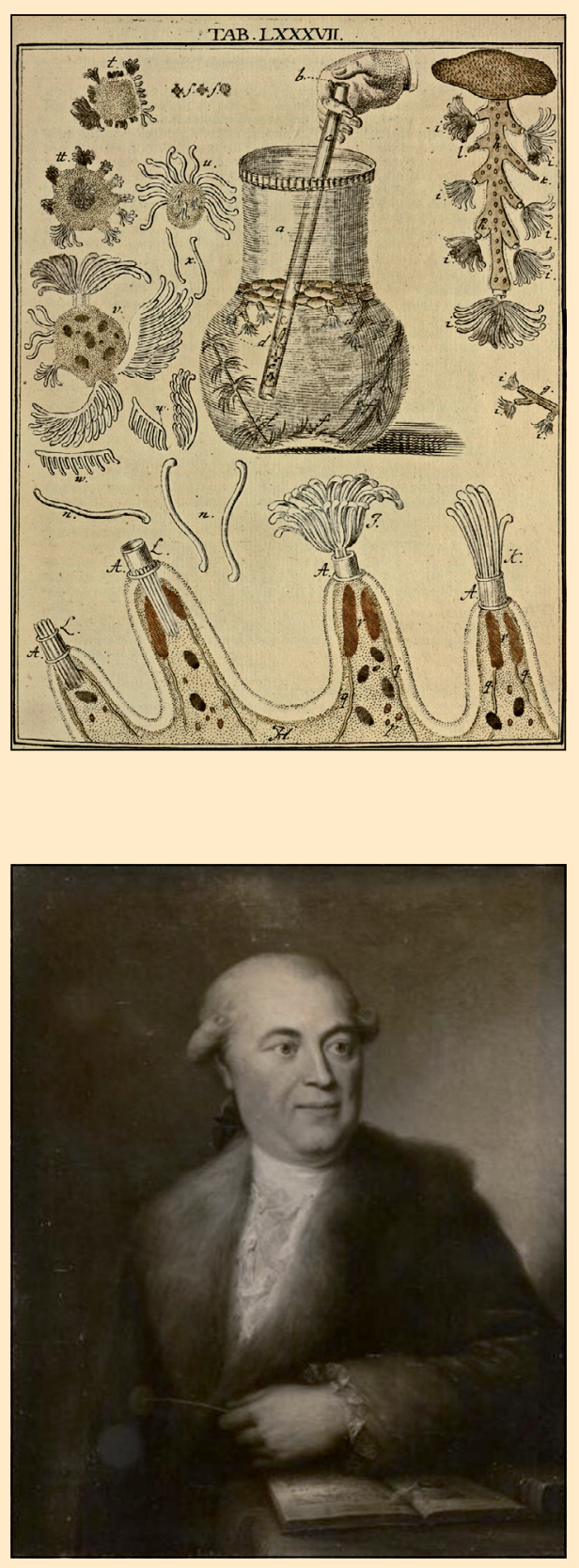

agudeza de los ojos y el hablar no tendría fin. La mente humana es capaz de presentar poquísimas lecciones sobre la magnificencia y esplendor del poder divino; en la mayoría de los casos queda estupefacta y enmudece".

"El mundo de las cosas invisibles oculto para los antiguos, desde hace cien años empezó a develarse, proporcionando maravillas inauditas en forma y razón de vida...".

(Traducción literal del original en latín).

En esta obra describió al género Monas como: vermis inconspicuus, simplicissimus, pellucidus, punctiformis (gusanos inconspicuos, simplísimos, trasparentes y puntiformes) y nombró 10 especies. El género Vibrio fue descrito como: vermis inconspicuus, simplicissimus, teres, elongatus (se agregan a lo anterior las características de cilíndrico y elongado), describiendo seis especies. Dos nombres de estas nuevas especies perdurarían: Vibrio bacillus y Vibrio spirillum. Además, incorporó al género Proteus describiéndolo como: vermis inconspicuus, simplicissimus, pellucidus, mutabilis (con la característica de cambiante o variable). En este momento es importante relevar al menos dos puntos de especial interés. Primero, es probable que los géneros creados por Müller no incluyesen exclusivamente bacterias sino también pequeños eucariontes, pues las técnicas microscópicas del momento no eran muy avanzadas y la diferenciación tajante entre los conceptos de procarionte y eucarionte, que recién comenzaría a aclararse con el botánico Ferdinand Cohn (ver más adelante), aún debería esperar más de un siglo su firme consolidación con los trabajos del destacado biólogo francés Edouard Chatton ${ }^{12}$. En segundo lugar, es destacable que Müller haya ubicado a todos estos nuevos grupos dentro de la clase de los Vermes o gusanos, a su vez dentro del reino Animalia, siguiendo así la senda trazada por Linnaeus.

Figura 2. Otto Friedrich Müller (17301784). Afamado microscopista danés. Su obra presenta el primer esfuerzo sistematizador de los infusorios o animalículos (Fuente: The Royal Library, Denmark).

avanzar con éxito más allá de las simples agrupaciones creadas por dichos autores. Su principal obra de interés microbiológico -titulada "Animalcula infusoria fluviatilia et marina" (Sobre animáliculos infusorios fluviales y marinos)- fue publicada de manera póstuma en $1786^{11}$. En el inicio del prefacio de esta obra el autor describe al mundo microbiano con estas bellísimas palabras:

"Si las cosas que se pueden decir de los animalículos infusorios se narraran en detalle, bastarian palabras y la

\section{Christian G. Ehrenberg}

Este gran científico y microscopista alemán puede ser considerado el continuador de la obra de Müller y como éste uno de los padres fundadores de la Bacteriología y Protozoología (Figura 3). Nació en la ciudad de Delitzsch en Sajonia, Alemania, en 1795. Realizó entre 1820-1825 expediciones a África y Medio Oriente donde pudo recolectar extensas muestras de animales y plantas. En 1827 fue nombrado Profesor de Medicina en la Universidad de Berlín, donde trabajó por el resto de su vida hasta su muerte acaecida en 1876. Después de sus investigaciones iniciales en plantas y animales, prontamente su interés se centró en el mundo microscópico. En su famosa obra publicada en 1838 titulada: "Die Infusionsthierchen als vollkommene Organismen” (Los animalículos infusorios 
como organismos perfectos) $)^{13}$, designa a los infusorios dentro de la clase Polygastrica, pues postula que poseen varios estómagos y otros diversos órganos, organizándose como animales perfectos y completos al igual que los grandes animales (en alemán vollkommene significa perfecto, ideal, completo). Dentro de esta clase reconoce 22 familias, siendo las de mayor interés bacteriológico la primera Monadina y la cuarta Vibrionia. En la familia Monadina describió 41 especies y nueve géneros, conteniendo principalmente bacterias de morfología cocoide. El organismo más pequeño descrito hasta entonces fue llamado sugestivamente por Ehrenberg Monas crepusculum. La cuarta familia Vibrionia (en alemán Zitterthierchen o en castellano animalitos vibradores) incluyó cinco géneros que pasarían a la posteridad: Bacterium, Vibrio, Spirochaeta, Spirillum y Spirodiscus. Esta familia contenía principalmente bacterias con morfología alargada o bacilar. Dada su trascendencia, en esta revisión se analizará sólo el origen del nombre del primer género mencionado. La denominación del género Bacterium es de origen latino y significa bastón o bastoncito (forma neutra y singular). Esta forma latina deriva de la palabra griega "bakterion" (diminutivo) cuyo significado es bastoncito. Dicha palabra deriva a su vez del griego "baktron", cuyo significado literal es bastón. La palabra "bacteria", la más utilizada actualmente, corresponde a la forma neutra y plural del término latino "bacterium" y su significado exacto corresponde a "bastones o bastoncitos". Ehrenberg fue el primero en introducir esta palabra al

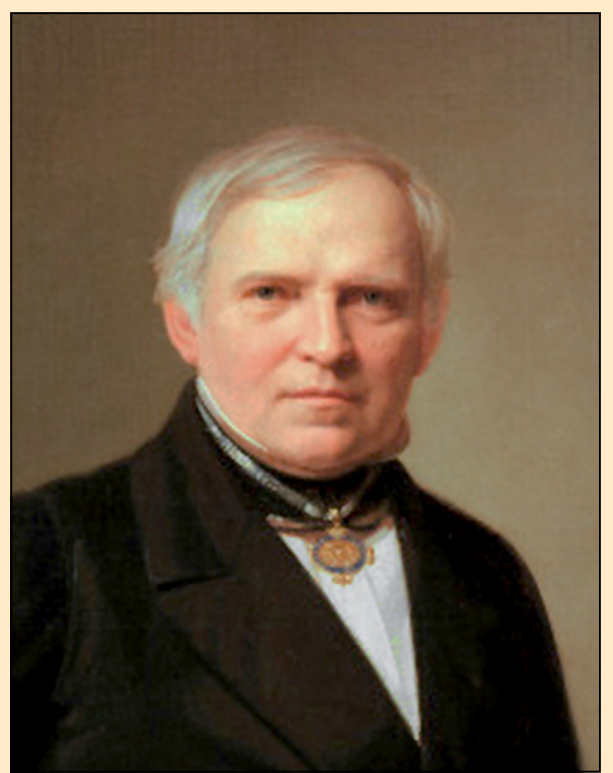

Figura 3. Christian Gottfried Ehrenberg (1795-1876). Gran naturalista y microscopista alemán. Continuó los trabajos de Müller sobre sistemática y propuso un nuevo esquema clasificatorio de los infusorios (Fuente: enciclopedia Wikipedia). léxico microbiológico. Sin embargo, su introducción al mundo biológico ocurrió unos años antes en 1825. El entomólogo francés Pierre André Latreille (1762-1833) utilizó por primera vez esta palabra para designar una especie de insecto de la clase Phasmatodea, es decir, el insecto alargado que vulgarmente denominamos en Chile "palote". En este punto se requiere una pequeña reflexión. Müller había acuñado ya el término bacillus como una especie del género Vibrio. Este término deriva del diminutivo de la palabra latina baculum que significa bastón y por lo tanto tiene el mismo significado que bacterium. Una posible explicación de esta aparente redundancia, es que Ehrenberg conservó en su clasificación la especie Vibrio bacillus, descrita previamente por Müller, por lo que habría requerido incorporar una nueva palabra para denominar a otra clase de bastoncitos que él describió como un nuevo género. Como se puede observar existe una similitud evidente entre las palabras baculum y bacterium, pues se postula que ambas tienen un ancestro común en la lengua proto-indoeuropea cuyo significado original era bastón.

\section{La denominación de bacteria como unidad taxonómica mayor}

No es fácil dilucidar la senda que siguió esta nueva palabra y comprender cómo desde un simple género microbiano se transformó en la denominación de todo un grupo de seres vivos que hoy, en la clasificación tripartita moderna de los seres vivos, tiene el más alto rango taxonómico denominado Dominio ${ }^{14}$. El primer ascenso taxonómico de las bacterias se debe al alemán Maximilian Perty (1804-1884) que en 1852 incorporó en una nueva clasificación, dentro de la familia Vibrionida, una subfamilia denominada Bacterina ${ }^{15}$. Posteriormente, el investigador francés Casimire J. Davaine (1812-1882) a inicios de la década de 1850 , desde el campo de las investigaciones sobre el origen de las enfermedades infecciosas -en particular la enfermedad de ántrax- describió cuerpos similares a bastones (petit corps filiformes) en ovejas muertas de esta enfermedad que denominó de manera general "bacteria" y luego "bacteridia"16. De esta forma, este término aún poco difundido adquirió gran notoriedad en la comunidad microbiológica de la época. Por otra parte, el botánico alemán Ferdinand Cohn (1828-1898) estableció en 1854 que la familia Vibrionia de Ehrenberg (no así la familia Monadina, probablemente por ser un grupo muy heterogéneo o polifilético) debería ser clasificada dentro del reino vegetal y por ello dejar de ser parte del grupo de los Vermes en el reino Animalia (Figura 4). Su justificación se basó en estudios acuciosos que demostraron que esta familia, como grupo, presentaba estrechas similitudes con algas microscópicas (i.e. cianobacterias). Finalmente, 
Figura 4. Ferdinand Cohn (1828-1898). Famoso botánico alemán. Muchos lo consideran el padre de la Bacteriología moderna (Fuente: enciclopedia Wikipedia).

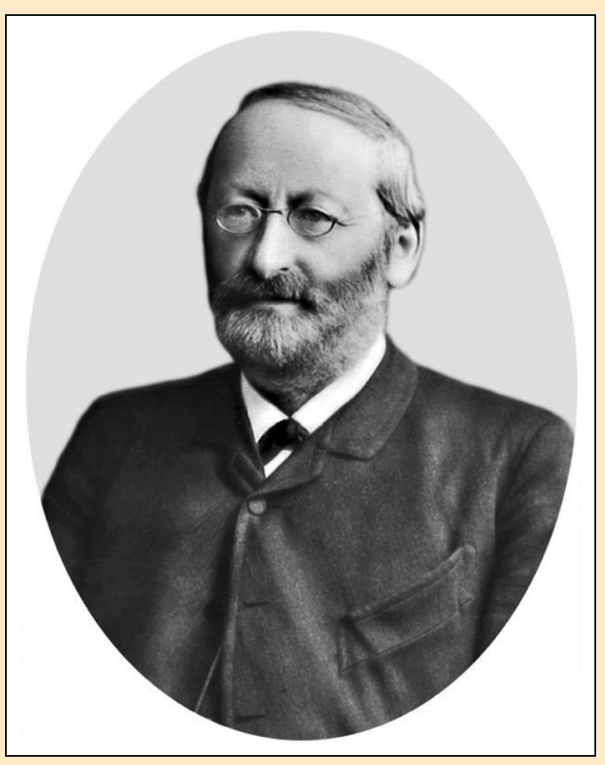

su famosa obra titulada "Untersuchungen über Bacterien" (Investigaciones sobre bacterias), publicada por primera vez en 1872, consolidó el nombre acuñado por Ehrenberg, Perty y Davaine para este grupo de seres vivos ${ }^{17,18}$. Cuáles fueron las razones últimas que motivaron a Cohn a denominar a este especial grupo de seres vivos como bacterias y no vibriones no se conocen a cabalidad. Seguramente consideraciones psicológicas, lingüísticas, históricas y de otra índole contribuyeron a ello. La transformación del nombre acuñado originalmente por Ehrenberg para un género particular, en un nombre para denominar un grupo taxonómico mayor trajo incongruencias semánticas que deberían haber sido evidentes. Pocos parecen darse cuenta hoy que denominar bacterias ("bastoncitos") a los cocos con morfología esférica es similar a querer cuadrar el círculo. Los cocos no deberían ser bacterias! Si se quiere plantear el problema en otros términos, sería lo mismo que clasificar a los cuerpos esféricos como dentro de la clase de cuerpos cuboidales o viceversa. Recordemos que las bacterias con morfología cocoide eran clasificadas por Ehrenberg dentro de la familia Monadina y las formas bacilares en la familia Vibrionia. El hecho de denominar a todo el grupo "bacteria", incorporando las formas cocoides, era evidentemente contradictorio. Así, se intentó deliberadamente vaciar de su significado original a la palabra "bacteria" y reasignar para el tipo de morfología filiforme o alargada el término "bacilo", acuñado originalmente por Müller para la especie Vibrio bacillus. El intento fue exitoso y ya nadie objeta esta contradicción. Si la elección de Cohn hubiese sido diferente, hoy nuestra área de estudio podría ser perfectamente conocida como Vibriología y así nadie podría acusarnos de denominar bastones a las formas que a todas luces son cocos.
Agradecimientos. Quisiera agradecer a varios colegas del Programa de Microbiología del Instituto de Ciencias Biomédicas (ICBM) que accedieron a leer y criticar este trabajo y así ayudaron a mejorar sustancialmente su presentación. También agradezco al Sr. Javier Osorio Naranjo, por su inestimable ayuda en traducir los textos originales en latín.

\section{Resumen}

Esta revisión analiza el origen del término "bacteria", creado por el insigne microbiólogo alemán Cristián G. Ehrenberg para denominar inicialmente a un simple género de la familia Vibrionia y finalmente de qué manera este nombre se impuso como la denominación formal para todo este grupo de seres vivos.

\section{Referencias bibliográficas}

1.- Dobell C. Antony van Leeuwenhoek and his little animals. Being some account of the father of Protozoology and Bacteriology and his multifarious discoveries in these disciplines. Constable and Company Ltd., London 1932. Dover Publications Inc., New York, 1960.

2.- Joblot L. Descriptions et usages de plusieurs nouveaux microscopes. 1718. Documento digital formato PDF: Gallica, Biblioteca Nacional de Francia: http://gallica.bnf.fr/. (accedido el 15 de diciembre de 2016).

3.- Ratcliff M J. The quest for the invisible. Microscopy in the enlightenment. MPG Books Ltd, Bodmin, Cornwall, Great Britain, 2009.

4.- Ledermüller M F. Mikroskopische Gemüths-und AugenErgötzung. 1760. Documento digital formato PDF: Bayerische Staats Bibliothek digital: https://www.bsbmuenchen.de/ (accedido el 15 de diciembre de 2016).

5.- Wrisberg H A. Observationum de animalculis infusoriis satura. 1765. Documento digital formato PDF: Gallica, Biblioteca Nacional de Francia: http://gallica.bnf.fr/ (accedido el 10 de octubre de 2016).

6.- Osorio G. Sobre agentes infecciosos, zoofitos, animálculos e infusorios. Rev Chilena Infectol 2007; 24: 171-4.

7.- Linnaeus C. Systema Naturae per Regna Tria Naturae, Secundum Classes, Ordines, Genera, Species, cum Characteribus, Differentiis, Synonymis, Locis. Tomus I, Editio Duodecima, Reformata, 1766. Documento digital formato PDF: Gallica, Biblioteca Nacional de Francia: http:// gallica.bnf.fr/ (accedido el 3 de octubre de 2015).

8.- Ragan M. A third kingdom of eukaryotic life: history of an idea. Arch Protistenkd 1997; 148: 225-43.

9.- Linnaeus C. Mundus invisibilis. Amoenitates academicae. Documento digital formato PDF: Digizeitschriften: https:// www.digizeitschriften.de/dms/toc (accedido el 10 de noviembre de 2016).

10.- Müller O F. Vermium Terrestrium et Fluviatilium, seu Animalium Infusoriorum, Helminthecorum, et Testaceorum non Marinorum, succincta Historia, 1773. Documento digital formato PDF: https://www.sub.uni-goettingen.de/en/digitallibrary/e-resources/ (accedido el 20 de junio de 2014). 
11.- Müller O F. Animalcula infusoria; fluviatilia et marina, quae detexit, systematice descrpsit et ad vivum delineari curavit. 1786. Documento digital formato PDF: Göttingen University Library, Germany: https://www.sub.uni-goettingen.de/ en/digital-library/e-resources/ (accedido el 20 de junio de 2014).

12.- Chatton E. Pansporella perplexa. Reflexions sur la biologie et la phylogenie des protozoaires. Ann Sci Nat Zool 1925; 10e serie; VII: 1-84.

13.- Ehrenberg C G. Die Infusionsthierchen_als_vollkommene_ Organismen. Documento digital formato PDF: Gallica, Biblioteca Nacional de Francia: http://gallica.bnf.fr/ (accedido el 1 de octubre de 2016).

14.- Woese C R. Kandler O, Wheelis M L. Towards a natural system of organisms: Proposal for the domains Archaea, Bacteria, and Eucarya. Proc Natl Acad Sci USA 1990; 87:
4576-9.

15.- Perty M. Zur Renntniss kleinster Lebenformen nach Bau, Funktionen, Systematik, mit specialverzeichniss der in der Schweiz. Documento digital formato PDF: http://img.algaebase.org/pdf/ AC100CF00290f16923TYT172E767/24263.pdf (accedido el 10 de noviembre de 2016).

16.- Davaine C. Recherches sur les infusoires du sang dans la maladie connue sous le nom de sang de rate. Comptes Rendus de l'Academie des Sciences (Paris) 1863. 57: 220-3; 351-3.

17.- Cohn F. Untersuchungen über Bacterien. Documento digital formato PDF: http://www.biodiversitylibrary.org (accedido el 10 de noviembre de 2016).

18.- Bulloch W. The History of Bacteriology. Oxford University Press, First Edition, London, England, 1938. 